2019-09-11

\title{
Examining the type and frequency of incidents attended by UK paramedics
}

\author{
Henderson, Tristan
}

http://hdl.handle.net/10026.1/13351

10.12968/jpar.2019.11.9.396

Journal of Paramedic Practice: the clinical monthly for emergency care professionals

Mark Allen Healthcare

All content in PEARL is protected by copyright law. Author manuscripts are made available in accordance with publisher policies. Please cite only the published version using the details provided on the item record or document. In the absence of an open licence (e.g. Creative Commons), permissions for further reuse of content should be sought from the publisher or author. 


\section{Journal of Paramedic Practice}

Type and frequency of incidents attended by UK paramedics: patient record review in urban and rural ambulance stations in the South West of England. --Manuscript Draft--

\begin{tabular}{|c|c|}
\hline Manuscript Number: & jpar.2018.0051R2 \\
\hline Full Title: & $\begin{array}{l}\text { Type and frequency of incidents attended by UK paramedics: patient record review in } \\
\text { urban and rural ambulance stations in the South West of England. }\end{array}$ \\
\hline \multicolumn{2}{|l|}{ Short Title: } \\
\hline Article Type: & Research \\
\hline Keywords: & $\begin{array}{l}\text { *Incident frequency } \\
\text { *Incident type } \\
\text { *Paramedic incidents } \\
\text { *Paramedic scope of practice } \\
\text { * Skill decay/redundancy } \\
\text { *Skill frequency }\end{array}$ \\
\hline Corresponding Author: & $\begin{array}{l}\text { Tristan Henderson, BSc (Hons) } \\
\text { University of Plymouth } \\
\text { Plymouth, Devon UNITED KINGDOM }\end{array}$ \\
\hline \multicolumn{2}{|l|}{$\begin{array}{l}\text { Corresponding Author Secondary } \\
\text { Information: }\end{array}$} \\
\hline Corresponding Author's Institution: & University of Plymouth \\
\hline \multicolumn{2}{|l|}{$\begin{array}{l}\text { Corresponding Author's Secondary } \\
\text { Institution: }\end{array}$} \\
\hline First Author: & Tristan Henderson, BSc (Hons) \\
\hline \multicolumn{2}{|l|}{ First Author Secondary Information: } \\
\hline \multirow[t]{4}{*}{ Order of Authors: } & Tristan Henderson, BSc (Hons) \\
\hline & Ruth Endacott, Dr \\
\hline & Jonathan Marsden, Dr \\
\hline & Sarah Black, Dr \\
\hline \multicolumn{2}{|c|}{ Order of Authors Secondary Information: } \\
\hline Abstract: & $\begin{array}{l}\text { Various factors have widened the variety of incidents that UK paramedics, practicing in } \\
\text { a non-specialist role may be required to attend. } \\
\text { This study set out to identify the type and frequency of incidents attended by } \\
\text { paramedics, as well as establishing whether geographical location and time of year } \\
\text { bear any influence. It also sought to highlight potential issues raised by the findings. } \\
\text { The study involved quantitative retrospective review of Paramedic completed patient } \\
\text { clinical records, across two locations and over one year. } \\
\text { Results demonstrated the infrequent exposure of paramedics to serious illness/trauma, } \\
\text { as well as limited associations of significance in relation to location and time of year. } \\
\text { The infrequent nature of certain incidents raises potential issues of skill decay for } \\
\text { paramedics, closely aligned to this is their education, and how learning is best } \\
\text { balanced between the infrequent, serious presentations and those that are frequent but } \\
\text { less serious. }\end{array}$ \\
\hline \multicolumn{2}{|l|}{ Response to Reviewers: } \\
\hline \multicolumn{2}{|l|}{ Additional Information: } \\
\hline Question & Response \\
\hline
\end{tabular}


Type and frequency of incidents attended by UK paramedics: patient record review in urban and rural ambulance stations in the South West of England.

\author{
Authors \\ Henderson, Tristan - Academic Lead for Paramedicine, University of Plymouth \\ Endacott, Ruth - Professor in Clinical Nursing (Critical Care), University of Plymouth \\ Marsden, Jonathan - Professor in Rehabilitation, University of Plymouth \\ Black, Sarah - Head of Research, Audit and Quality Improvement, South Western \\ Ambulance Service NHS Foundation Trust
}

\title{
Conflict of interest statement
}

Tristan Henderson and Sarah Black are employed by the ambulance service where this research was conducted; however, there was no personal or financial gain in their involvement and the results have been accurately reported following verification by a third party (as stated in the article). 


\section{Abstract}

Various factors have widened the variety of incidents that UK paramedics, practicing in a non-specialist role may be required to attend.

This study set out to identify the type and frequency of incidents attended by paramedics, as well as establishing whether geographical location and time of year bear any influence.

The study involved quantitative retrospective review of Paramedic completed patient clinical records, across two locations and covering one year.

Results demonstrated the infrequent exposure of paramedics to serious illness/trauma as well as limited associations of significance in relation to location and time of year.

The infrequent nature of certain incidents raises potential issues of skill decay for paramedics, closely aligned to this is their ongoing education, and how learning is best balanced between the infrequent, serious presentations and those that are frequent but less serious. 


\section{Keywords/Terms}

- Incident frequency

- Incident type

- Paramedic incidents

- Paramedic scope of practice

- Skill decay/redundancy

- Skill frequency

\section{Key Points}

- Exposure to critically ill/injured patients is rare for UK paramedics

- The most commonly attended incidents for UK paramedics, based on provisional diagnosis codes, are largely medical and tend to be nebulous in nature

- Types of incident attended are not influenced by time of year or geographical location

- The infrequency of some incidents gives cause for concern about skill retention in UK paramedics

\section{Reflective questions}

- What types of incidents do you regularly attend?

- What differences can you identify in the management of time critical and non-time critical patients

- How often do you attend seriously ill/injured patients?

- How confident/competent do you feel in the management of the critically ill/injured patient?

- How confident/competent do you feel in the management of minor illness/injury? 


\section{Introduction}

Paramedicine, like just a few other medical professions has a nature which is 'specialist generalist' (College of Paramedics (CoP), 2015; CoP, 2013). As such, paramedics are expected to be able to manage any patient they are presented with, from minor to major illness or injury (CoP, 2017; Department of Health (DH), 2005). This broad scope of practice may present issues for paramedics when the infrequent nature of some incidents such as major trauma and cardiac arrest is considered (National Audit Office (NAO), 2010;

$\mathrm{DH}, 2005)$. In addition to, and compounding this, within a changing National Health Service (NHS), there are various historical and contemporary political drivers altering the practice landscape, and therefore incidents attended by paramedics (NHS England, 2015; Association of Ambulance Chief Officers (AACE), 2011; DH, 2005).

The 2005 report on a strategic review of ambulance services, Taking Healthcare to the Patient (DH, 2005), started one such drive that still exists today. It aimed to see patients treated at home where safe to do so, rather than arbitrarily transferring them to hospital, as had traditionally happened. This same publication estimated that $20 \%$ of the wider NHS patients could be treated in the community, a more recent study by Dixon and Gaisford (2014), carried out in the same trust as this research, established non-specialist paramedic non-conveyance rates to be $27 \%$.

The drive to discharge more patients on scene, as well as the potential infrequency of managing the critically ill/injured patient highlights the requirement for a developing skill set in paramedicine, so that these patients 
can be safely and effectively managed. Although the Specialist Paramedic role has been widely discussed in contemporary literature as a way of refining skills in order to maintain competence and provide a quality service to the public (Newton and Hodge, 2012), the focus of this current work is on the nonspecialist paramedics and the incidents they attend.

In addition to the above, there are raised public expectations in relation to the skill-set of paramedics and incidents they can manage, largely due to the ease of access to online medical information (Edwards, 2014; Lowry and Anderson, 2006).

These factors combine to make the traditional, non-specialist paramedic role more complex and challenging than it has ever been before, both in the context of expected skills ability, and types of incidents they are expected to manage. (CoP, 2017; CoP, 2013; NHS England, 2013a, NHS England 2013b, AACE, 2011; DH, 2005).

\section{Aims \& Objectives}

The aim of this study is to identify the frequency of incidents attended with a view to highlighting potential issues that may exist for paramedic practice. This aim will be achieved through the following objectives;

- Identify the frequency of attendance at specific incidents by paramedics in a large UK ambulance service trust

- Establish whether there are any temporal or geographical features which impact on the type of incidents attended 
- Identify potential issues with skill decay/redundancy for paramedics in their current role

\section{Methods}

\section{Design}

A quantitative retrospective review of paramedic completed patient clinical records (PCRs) seeking to identify information in relation to types of incident attended by paramedics.

\section{Inclusion / Exclusion}

All PCRs reviewed were completed by paramedics, practicing in a non-specialist role, working in one of two pre-identified areas, within the local ambulance service trust.

Exclusion criteria during data collection were;

- Non-paramedic completion of the PCR

- Non-conveyance to hospital

- Lack of clarity over the vehicle call-sign and therefore origin of the attending vehicle

Non-conveyance was excluded as it was felt it would be less likely that this patient group would undergo clinical intervention.

A reason was recorded for all excluded incidents during data collection.

PCR Sample

The sample size was six-hundred PCRs; this was designed to identify incidents and skills occurring in $5 \%$ or more of ambulance service activity, with precision of $0.025 \%$ (Naing, Winn \& Rusli, 2006). 
The sample was split equally between PCRs completed in rural and urban areas; the decision about the specific areas used was made in consultation with the Research \& Audit department of the local ambulance trust, based on the procedures involved with their PCR collection and processing. This collaboration allowed for the most contemporaneous sample possible, May 2013 to April 2014. Within each of the selected geographical areas an equal number of clinical records were randomly selected from each month $(n=25)$.

To achieve this random sample, chronological lists of all incident numbers for each location and month were created, these were then randomised in terms of order, creating non-chronological lists of incident numbers for each of the months within each location. These lists were then used, working top to bottom, to identify PCRs for data collection. When twenty-five suitable records had been selected for each month, at each ambulance station, they were then redacted to conceal any nonessential, sensitive data.

\section{Data Collection}

The data was collected and recorded using a custom designed data collection tool, informed by the design of the clinical record being reviewed. This is split into two main sections, 'tick box' and 'free text'. The skills chosen were those that were technical and required marking of a tick-box to record completion; it was felt that this would be more reliable in relation to accurate data collection and measurement.

During data collection, $8.3 \%(n=50)$ clinical records were reviewed by an independent researcher against the data collection tool to verify reliability; in 
addition, frequency analysis was employed by the chief investigator to identify errors (Gray, 2009).

There was minimal control over missing data during collection; largely a result of the study design, retrospective review; this would suggest any omission of data was not deliberate.

\section{Incident Categories}

The collected data were used to look at frequency of incident types and the factors that may influence variation.

Eighty-nine separate provisional diagnosis codes, out of the one hundred and fortyfive used by the trust in question, were identified during data collection. Due to the size of this data-set, the eighty-nine codes were re-considered under eight, more manageable broad groups (see table 1) for some aspects of analysis. These revised groups were informed by the general groups that the provisional diagnosis codes fall into, for example cardiac arrest and angina would be within the Cardiac group. The groups were duplicated from the trust PCR pads.

\begin{tabular}{|c|c|}
\hline \multicolumn{2}{|c|}{ Table 1, Broad Incident Groups } \\
\hline Full Name & Abbreviation \\
\hline Cardiac & Cardiac \\
\hline Gastrointestinal & Gl \\
\hline Neurological & Neuro \\
\hline Other & Other \\
\hline Other Medical & Oth Med \\
\hline Psychiatric/Mental Health & Psych/MH \\
\hline Respiratory & Resp \\
\hline Trauma (injury) & Trauma \\
\hline
\end{tabular}


Most of the categories are self-explanatory; however, 'other' and 'other medical' are less intuitive. Table 2 offers detail of these groups.

\begin{tabular}{|c|c|}
\hline \multicolumn{2}{|c|}{ Table 2, Other/Other Medical Broad Incident Group Details } \\
\hline Other & Other medical \\
\hline Obstetrics/Gynaecology & Hypo/Hyperglycaemia \\
\hline Poisoning (accidental) & Syncope \\
\hline Environmental & Allergic reaction \\
\hline Social & Epistaxis \\
\hline Other & Urinary tract infection \\
\hline & Sepsis \\
\hline & Anaphylaxis \\
\hline
\end{tabular}

Data Analysis

The data were initially analysed using descriptive statistics, this approach provided an overview of incident types, location and time of year. The chi-square test was then used to establish relationships between categorical variables such as incident type and time of year. 


\section{Results}

Frequency of Broad Incident Groups

Table 3 Shows the frequencies of the broad incident categories for the rural and urban areas combined.

\begin{tabular}{|c|c|}
\hline \multicolumn{2}{|c|}{ Table 3, Broad Incident Group Frequency } \\
\hline Broad Incident Code & Frequency \\
\hline Trauma & $24 \%(n=144)$ \\
\hline Other Medical & $18.5 \%(n=111)$ \\
\hline Gastrointestinal & $14.5 \%(n=87)$ \\
\hline Cardiac & $14 \%(n=87)$ \\
\hline Respiratory & $10.3 \%(n=62)$ \\
\hline Neurological & $7.5 \%(n=45)$ \\
\hline Other & $5.7 \%(n=34)$ \\
\hline Psychiatric/Mental Health & $5.2 \%(n=31)$ \\
\hline
\end{tabular}

In general, trauma was the largest broad category of incidents encountered by paramedics, $24 \%(n=144)$. This is a very diverse group that consists of both minor trauma and major/multi-system trauma, possibly explaining its high frequency.

Continued review of the subsequent broad groups shows 'other medical' was the second largest group, $18.5 \%(n=111)$. Again, this is a diverse group that represents multiple different medical conditions such as diabetic emergencies, sepsis, epistaxis, UTIs, syncope and more. In addition, it perhaps reflects increased calls to the 
ambulance service for minor illness that would traditionally have been seen in primary care.

Gastrointestinal and Cardiac incidents have the next highest frequencies, $14.5 \%$ $(n=87)$ and $14 \%(n=84)$ respectively. Notably within the category of cardiac incidents, cardiac arrests were only identified in $0.5 \%(n=3)$ of the incidents reviewed.

Analysis of broad incident types in relation to the geographical area shows slight variance between urban and rural areas, this can be seen in table 4 . The urban data mimics that of the combined picture; however, for the rural area, the frequency of cardiac and GI incidents were reversed. These differences were not found to hold statistical significance, $X^{2}=10.15, p=0.18$.

\begin{tabular}{|l|l|l|}
\hline \multicolumn{3}{|c|}{ Table 4, Location and Frequency of Incident Type } \\
\hline \multicolumn{1}{|c|}{ Broad Incident Group } & \multicolumn{1}{|c|}{ Rural Frequency } & \multicolumn{1}{c|}{ Urban Frequency } \\
\hline Trauma & $22.3 \%(n=67)$ & $26.3 \%(n=79)$ \\
\hline Other Medical & $19.6 \%(n=59)$ & $17.3 \%(n=52)$ \\
\hline Gastrointestinal & $14 \%(n=42)$ & $15 \%(n=45)$ \\
\hline Cardiac & $16.6 \%(n=50)$ & $11.3 \%(n=34)$ \\
\hline Respiratory & $11.6(n=35)$ & $9 \%(n=27)$ \\
\hline Neurological & $7.6 \%(n=23)$ & $7.3 \%(n=22)$ \\
\hline Other & $4 \%(n=12)$ & $7.3 \%(n=22)$ \\
\hline Psychiatric/Mental Health & $4 \%(n=12)$ & $6.3 \%(n=19)$ \\
\hline
\end{tabular}

When broad incidents types and season were analysed, there was an increase in trauma frequency during the summer months; although, this was not found to hold significant difference, $X^{2}(21, n=600)=15.283, p=0.809$. 
Frequency of Provisional Diagnosis Codes

When frequency of incident was reviewed in terms of the more specific ambulance service provisional diagnosis codes, a different picture emerges. Table 5 shows the most frequently attended codes for all urban and rural records combined ( 1 being the most common). Contrary to the broad groups, there is no trauma code within the more focused provisional diagnosis codes, all are medical.

\begin{tabular}{|c|c|c|}
\hline \multicolumn{3}{|c|}{ Table 5, Common Provisional Diagnosis Codes } \\
Frequency & $\begin{array}{c}\text { Provisional Diagnosis } \\
\text { Code/Condition }\end{array}$ & $\begin{array}{c}\text { Percentage of incidents } \\
\text { reviewed (out of 600 records) }\end{array}$ \\
\hline $\mathbf{1}$ & M21 - Acute abdomen & $8.3 \%(n=50)$ \\
\hline $\mathbf{2}$ & M58 - Medical Other & $7.3 \%(n=44)$ \\
\hline $\mathbf{3}$ & M15 - Acute coronary syndrome & $4.8 \%(n=29)$ \\
\hline $\mathbf{4}$ & M05 - Chest infection & $3 \%(n=25)$ \\
\hline $\mathbf{5}$ & M62 - Sepsis & $3.2 \%$ \\
\hline
\end{tabular}

In total eighty-nine different provisional diagnosis codes were recorded through the six hundred PCRs, the top three are more expansive conditions (as identified with the broad groups). The top five provisional diagnosis codes accounted for $27.6 \%$ $(n=166)$ of all the incidents reviewed.

When provisional diagnosis codes are explored in the context of geographical location, there seems to be more variance than with the broad groups, albeit still not statistically significant. Table 6 shows the top five occurring provisional diagnosis codes for each geographical location. 


\begin{tabular}{|c|c|c|}
\hline \multicolumn{3}{|c|}{ Table 6, Common Provisional Diagnosis Codes and Location } \\
\hline $\begin{array}{c}\text { Order of } \\
\text { Frequency }\end{array}$ & $\begin{array}{c}\text { Urban Station } \\
\text { (prov diag code, \% frequency) }\end{array}$ & $\begin{array}{c}\text { Rural Station } \\
\text { (prov diag code, \% frequency) }\end{array}$ \\
\hline 1 & $\begin{array}{c}\text { M58 - Medical Other } \\
9 \%(n=27)\end{array}$ & $\begin{array}{c}\text { M21 - Acute abdomen } \\
10.6 \%(n=32)\end{array}$ \\
\hline 2 & $\begin{array}{c}\text { M21 - Acute abdomen } \\
6 \%(n=18)\end{array}$ & $\begin{array}{l}\text { M15 - Acute coronary syndrome } \\
\qquad 6 \%(n=18)\end{array}$ \\
\hline 3 & $\begin{array}{l}\text { M62 - Sepsis } \\
4 \%(n=12)\end{array}$ & $\begin{array}{c}\text { M58 - Medical Other } \\
5.6 \%(n=17)\end{array}$ \\
\hline 4 & $\begin{array}{c}\text { M15 - Acute coronary syndrome } \\
3.6 \%(n=11) \\
\text { M24 - Gastrointestinal other }(3.6 \% \\
n=11) \\
\text { T03A - Head wound } \\
3.6 \%(n=11)\end{array}$ & $\begin{array}{c}\text { M05 - Chest infection } \\
5 \%(n=15)\end{array}$ \\
\hline 5 & $\begin{array}{c}\text { D02 - Overdose (non opiate) } 3.3 \% \\
(n=10) \\
\text { M05- Chest infection } \\
3.3 \%(n=10)\end{array}$ & $\begin{array}{c}\text { M57 - Syncope (faint) } \\
4 \%(n=12)\end{array}$ \\
\hline
\end{tabular}

A greater number of provisional diagnosis codes make up the top five most frequent incidents within the urban area when compared to the rural setting.

The urban top five provisional diagnosis codes see the re-emergence of a trauma category (T03A - Head Wound), this was accompanied by the presence of sepsis, gastrointestinal other and overdose. These did not appear in the rural top five; however, syncope is common in the rural area, but not the urban setting. 
Review of specific provisional diagnosis codes in the context of the month, do not show significant difference. This is likely due to the size of the data set and the infrequent occurrence of many codes.

\section{Discussion}

When incident types were divided into broad, general categories, 'Trauma' was the most commonly occurring, $24 \%(n=144)$ of all records reviewed, this figure is not reflected by the AACE Academic review of demand (Edwards, 2014). Using data from five UK ambulance trusts, this review reported an incidence of $3.4 \%$ for 'traumatic injury' over the 2013-14 period. In the CoP Curriculum Guidance document (CoP, 2017), a slightly higher frequency for trauma incidents is reported by the South East Coast Ambulance Service, at $7.64 \%$. The large variation between the three sources is likely explained by the difference between the incident codes used for reporting.

Despite the seemingly high frequency of this group, at the most serious end of the scale, major trauma accounted for only $0.001 \%(n=1)$ of the six hundred records reviewed, the same can also be said of the multisystem trauma code.

For many years now, the infrequency of major trauma exposure has been documented. Comment has been made about the proportion of time during paramedic education/training (initial and on-going) spent preparing for incidents that they will encounter only very occasionally, and the stark infrequency of exposure to this patient group, less than one percent of a paramedics working time ( $\mathrm{DH}, 2005$; NCEPOD, 2007; RCS, 2009; NAO, 2010; CoP, 2013). This generates potential for paramedics to suffer skill decay due to infrequent exposure to the patient group and 
infrequent use of the skills required to manage them, such as intravenous cannulation, intraosseous access and advanced airway management. The ultimate risk is reduced standards of trauma care being offered by non-specialist paramedics within the UK, when compared to other countries (NCEPOD, 2007; RCS, 2009; NAO, 2010).

A similar situation arises with the infrequency of attendance at cardiac arrest incidents, only $0.5 \%(n=3)$ of the six hundred records reviewed recorded this provisional diagnosis code. Management of cardiac arrest is a skill often considered a staple of the Paramedic, perhaps due to an increasing number of 'fly on the wall documentaries' following paramedics, showing attendance at the most dramatic incidents, such as cardiac arrests. Similarly to the trauma related publications already mentioned, the DHs, 'Taking Healthcare to the Patient 1 \& 2 (DH, 2005; AACE, 2011), report on a strategic review of ambulance services and its subsequent progress six years on, identifying that life-threatening illness/injury accounts for up to ten percent of a paramedic's workload. Cardiac arrest obviously sits within this category, with many others and would therefore only make up a small proportion. The second report, Taking Healthcare to the Patient 2 (AACE, 2011), suggests that nationally, cardiac arrest patients make up approximately one percent of ambulance attendances, a slightly higher occurrence than was reflected in the six hundred records reviewed for this study. Again, the infrequency of this group creates potential for skill decay when carrying out certain procedures on the critically ill cardiac patient.

There has long been a drive to prepare paramedics for the workload that they will actually encounter (NHS England, 2015; CoP, 2013; DH, 2005), with suggestion that ambulance services need to change from a service providing resuscitation, to that of 
a mobile health resource responding to the varied, more regular needs of its patients. This sounds very simple; however, paramedics responding to incidents must still demonstrate competence when managing the rarely seen major/multisystem trauma patient or the cardiac arrest patient (CoP, 2017; HCPC, 2014).

The infrequency of incident types such as 'cardiac arrest' and 'major trauma' hold potential issues for the standard of care delivered by non-specialist paramedics. Pusic et al (2012), in a literature review, discuss the concept of forgetting curves; they assert that competence in clinical skills not practiced regularly, will deteriorate at an alarmingly fast rate initially before this deterioration slows down. This is likely to be more significant in more complex skills and those with a cognitive element; management of the critically ill/injured or the cardiac arrest patient fits this, infrequent, complex, cognitive criteria.

Discussion around forgetting curves suggests degradation stops at around the level of a novice; paramedics should therefore still be able to satisfy the regulatory body threshold standards (HCPC, 2014). However, it is unlikely that either they, or their patients would be satisfied with this in the context of increasing public expectation (Edwards, 2014).

The rate of degradation in performance is linked to the initial teaching or 'encoding'; this makes teaching and learning strategies vitally important (Pusic et al, 2012). Additionally, the opportunity for regular, 'deliberate' practice with feedback can be beneficial (Byrne, Pugsley and Hashem, 2008; Ericsson, 2004). It therefore seems reasonable to suggest that these two aspects in combination, have the potential to influence the trajectory of the forgetting curve. 
In the context of the most commonly encountered provisional diagnosis codes and their often, non-time critical nature, AACE (2011) highlights some potential issues, suggesting that these incidents can sometimes be more challenging to manage than time critical situations such as cardiac arrest, where decisions are often relatively binary and follow more intuitive and practical guidelines. It again raises questions about the balance of paramedic education and training, which historically spent a disproportionate amount of time preparing paramedics for life threatening emergencies (DH, 2005; AACE, 2011).

Patients not conveyed may be considered part of the non-time critical population. Non-conveyance of patients, although not included in this study, may still require the use of clinical skills, potentially within complex situations. Studies based in this study setting reported non-specialist paramedics non-conveyance rates of between 2732\% (Dixon and Gaisford 2014; Cooper et al, 2007), other UK studies have reported similar figures (Snooks et al, 2003). An international systematic review suggested that $52 \%$ of ambulance service use was unnecessary/inappropriate, this is different to specific conveyance rates but does have some obvious similarities (Mikolaizak et al, 2013). These figures suggest an additional source of data that may offer further insight into the issue of skills competence and confidence for the future.

Discussion around the complexities of managing specific patient groups safely and effectively, intuitively leads to acknowledgement of Specialist Paramedic roles such as Critical and Primary and Urgent care fields of practice. Literature has espoused the benefits to the patient of this (CoP, 2018; Newton and Hodge, 2012; AACE, 2011; DH, 2005); however, non-specialist paramedics practicing in the traditional 
role must still be able to manage all patients in the absence of a specialist. This means that the Specialist Paramedic role does not solve the issues raised by the frequency of incidents reported in all situations (CoP, 2017; HCPC, 2014).

Urban and rural populations can have a different demographic structure. Edwards (2014) highlights that more densely populated areas have a higher ambulance demand but did not go so far as differentiating between call types in each area. This suggests it is reasonable to conclude that rural, less populated areas, have a lower ambulance demand, maybe explaining the narrower variety of provisional diagnosis codes seen in the top five. Anecdotally, paramedics have considered that clinicians working in these two distinct areas are exposed to different workloads. There is no focused research within the UK to demonstrate this. When the data from this study was reviewed, there was no significant difference in the broad incident groups across locations; similarly, when incidents were reviewed in terms of the more specific provisional diagnosis codes across areas, despite some variance there was still no significant difference, as shown in the results section of this study.

\section{Conclusion}

Non-specialist paramedics are attending a wide range of incidents. Whether in terms of broad groups or provisional diagnosis codes, the most frequent incident types tend to be diverse in nature. There was no statistical significance found in difference between incident types attended and location or time of year. The study confirms previous literature in relation to the low frequency of incidents such as major/multisystem trauma and cardiac arrest. Furthermore, contemporary literature suggests there may be an issue in relation to skill retention at incidents that are only encountered rarely. This gives cause for careful consideration by 
paramedics and education providers about how clinicians practicing in a nonspecialist role will continue to meet the standards of proficiency as well as maintaining confidence and competence in their practice.

\section{Limitations}

A larger sample of PCRs would have offered a more detailed picture of the frequently attended provisional diagnosis codes which may have allowed for greater specificity during analysis. In addition, widening the data collection to include qualitative aspects of the PCR would also perhaps have offered better insight. The study design excluded patients not conveyed to hospital; however, inclusion of this group may have highlighted patterns and trends with skills used in these situations. The inclusion of this group would also have offered a more detailed insight into the wider frequency of incident types as a proportion, without this patient group removed from the sample. 


\section{References}

Association of Ambulance Chief Executives (2011) Taking Healthcare to the Patient

2: A review of six years progress and recommendations for the future. London: Association of Chief Ambulance Officers

Byrne, A. Jones, P. Pugsley, L (2009) The predictive value of self-assessed clinical skills competencies by graduate entry medical students. International Journal of Clinical Skills. 3 (1) 30-33

College of Paramedics (2013) The Paramedic Evidence Based Education Project. Bridgwater: College of Paramedics

College of Paramedics (2015) Paramedic - Scope of Practice Policy. Bridgwater: College of Paramedics

College of Paramedics (2017) Paramedic Curriculum Guidance (4 ${ }^{\text {th }}$ edn, revised). Bridgwater: College of Paramedics

College of Paramedics (2018) Post Registration - Paramedic Career Framework (4 $4^{\text {th }}$ edn). Bridgwater: College of Paramedics

Cooper, S. O'Carroll, J. Jenkin, A. Badger, B (2007) Collaborative practices in unscheduled emergency care: role and impact of the emergency care practitioner quantitative findings. Emergency Medicine Journal. Vol. 24, pp.630-633

Department of Health (2005) Taking Healthcare to the Patient: transforming NHS ambulance services. London: The Stationery Office (269299) 
Department of Health (2015) Transforming urgent and emergency care services in England. London. The Stationary Office (03926)

Dixon, M. Gaisford, M (2014) Comparison of paramedic practice with that of an emergency care practitioner. Journal of Paramedic Practice. Vol.6 No.7

Edwards, M (2014) Academic Review of Demand 2013/14. London: Association of Ambulance Chief Executives

Ericsson, K (2004) Deliberate Practice and the Acquisition and Maintenance of Expert Performance in Medicine and Related Domains. Academic Medicine. Vol. 79 , iss. Supplement, pp. s70-s81

Gray. D (2009) Doing Research in the Real World (2 ${ }^{\text {nd }}$ edn). London: Sage Health and Care Professions Council (2014) Standards of Proficiency. London: Health and Care Professions Council

Lowrey, W. Anderson, W (2006) The Impact of Internet Use on the Public Perception of Physicians: A Perspective from the Sociology of Professions Literature, Health Communication, 19:2, 125-131, DOI:

$10.1207 / \mathrm{s} 15327027 \mathrm{hc} 1902 \_4$

Mikolaizak, S. Simpson, P. Tiedemann, A. Lord, S. Close, J (2013) Systematic review of non-transportation rates and outcomes for older people who have fallen after ambulance service call-out. Australasian Journal on Ageing. Vol. 32, No.3, pp.147-157

Naing. L, Winn. T, Rusli. B (2006) Practical Issues in Calculating the Sample Size for Prevalence Studies. Archives of Orofacial Sciences. 2006; 1: 914 
National Audit Office (2010) Major Trauma Care in England. London: National Audit Office (HC213)

National Confidential Enquiry into Patient Outcome and Deaths (2007) Trauma: Who Cares? London: National Confidential Enquiry into Patient Outcome and Deaths

NHS England (2013a) High quality care for all, now and for future generations:

Transforming urgent and emergency care services in England - Urgent and Emergency Care Review End of Phase 1 Report. London: NHS England. Publication Gateway Reference 00691

NHS England (2013b) Urgent and Emergency Care Review - Evidence Base Engagement Document. London: NHS England. Publication Gateway Reference 00163

Newton, A. Hodge, D (2012) The ambulance service: the past, present and future. The Journal of Paramedic Practice. Vol.4, No.5, pp. 303-305

Pusic, M. Kessler, D. Szyld, D. Kalet, A. Pecaric, M. Boutis, K (2012) Experience Curves as an Organising Framework for Deliberate Practice in Emergency Medicine Learning. Academic Emergency Medicine. 19: 1476-1480

Royal College of Surgeons (2009) Regional Trauma Systems - Interim Guidance for Commissioners. London: Royal College of Surgeons 
Snooks, H. Dale, J. Hartley-Sharpe, C. Halter, M (2003) On-scene alternatives for emergency ambulance crews attending patients who do not need to travel to the accident and emergency department: a review of the literature. Emergency Medicine Journal. Vol. 21, pp. 212-215 


\begin{tabular}{|c|c|}
\hline \multicolumn{2}{|c|}{ Table 1, Broad Incident Groups } \\
\hline Full Name & Abbreviation \\
\hline Cardiac & Cardiac \\
\hline Gastrointestinal & Gl \\
\hline Neurological & Other \\
\hline Other & Oth Med \\
\hline Other Medical & Psych/MH \\
\hline Psychiatric/Mental Health & Resp \\
\hline Respiratory & Trauma \\
\hline Trauma (injury) &
\end{tabular}




\begin{tabular}{|c|c|}
\hline \multicolumn{2}{|c|}{ Table 2, Other/Other Medical Broad Incident Group Details } \\
\hline Other & Other medical \\
\hline Obstetrics/Gynaecology & Hypo/Hyperglycaemia \\
\hline Poisoning (accidental) & Syncope \\
\hline Environmental & Allergic reaction \\
\hline Social & Epistaxis \\
\hline Other & Sepsis \\
\hline & Medical other \\
\hline & Anaphylaxis \\
\hline
\end{tabular}




\begin{tabular}{|c|c|}
\hline \multicolumn{2}{|c|}{ Table 3, Broad Incident Group Frequency } \\
\hline Broad Incident Code & Frequency \\
\hline Trauma & $24 \%(n=144)$ \\
\hline Other Medical & $18.5 \%(n=111)$ \\
\hline Gastrointestinal & $14.5 \%(n=87)$ \\
\hline Cardiac & $14 \%(n=87)$ \\
\hline Respiratory & $10.3 \%(n=62)$ \\
\hline Neurological & $7.5 \%(n=45)$ \\
\hline Other & $5.7 \%(n=34)$ \\
\hline Psychiatric/Mental Health & $5.2 \%(n=31)$ \\
\hline
\end{tabular}




\begin{tabular}{|l|l|l|}
\hline \multicolumn{3}{|c|}{ Table 4, Location and Frequency of Incident Type } \\
\hline \multicolumn{1}{|c|}{ Broad Incident Group } & \multicolumn{1}{|c|}{ Rural Frequency } & \multicolumn{1}{c|}{ Urban Frequency } \\
\hline Trauma & $22.3 \%(n=67)$ & $26.3 \%(n=79)$ \\
\hline Other Medical & $19.6 \%(n=59)$ & $17.3 \%(n=52)$ \\
\hline Gastrointestinal & $14 \%(n=42)$ & $15 \%(n=45)$ \\
\hline Cardiac & $16.6 \%(n=50)$ & $11.3 \%(n=34)$ \\
\hline Respiratory & $11.6(n=35)$ & $9 \%(n=27)$ \\
\hline Neurological & $7.6 \%(n=23)$ & $7.3 \%(n=22)$ \\
\hline Other & $4 \%(n=12)$ & $7.3 \%(n=22)$ \\
\hline Psychiatric/Mental Health & $4 \%(n=12)$ & $6.3 \%(n=19)$ \\
\hline
\end{tabular}




\begin{tabular}{|c|c|c|}
\hline \multicolumn{3}{|c|}{ Table 5, Common Provisional Diagnosis Codes } \\
\hline $\begin{array}{l}\text { Order of } \\
\text { Frequency }\end{array}$ & $\begin{array}{l}\text { Provisional Diagnosis } \\
\text { Code/Condition }\end{array}$ & $\begin{array}{l}\text { Percentage of incidents } \\
\text { reviewed (out of } 600 \text { records) }\end{array}$ \\
\hline 1 & M21 - Acute abdomen & $8.3 \%(n=50)$ \\
\hline 2 & M58 - Medical Other & $7.3 \%(n=44)$ \\
\hline 3 & M15 - Acute coronary syndrome & $4.8 \%(n=29)$ \\
\hline 4 & M05 - Chest infection & $4.2 \%(n=25)$ \\
\hline 5 & M62 - Sepsis & $3 \%(n=18)$ \\
\hline
\end{tabular}




\begin{tabular}{|c|c|c|}
\hline $\begin{array}{c}\text { Order of } \\
\text { Frequency }\end{array}$ & $\begin{array}{c}\text { Urban Station } \\
\text { (prov diag code, \% frequency) }\end{array}$ & $\begin{array}{c}\text { Rural Station } \\
\text { (prov diag code, \% frequency) }\end{array}$ \\
\hline 1 & $\begin{array}{c}\text { M58 - Medical Other } \\
9 \%(n=27)\end{array}$ & $\begin{array}{c}\text { M21 - Acute abdomen } \\
10.6 \%(n=32)\end{array}$ \\
\hline 2 & $\begin{array}{c}\text { M21 - Acute abdomen } \\
6 \%(n=18)\end{array}$ & $\begin{array}{l}\text { M15 - Acute coronary syndrome } \\
\qquad 6 \%(n=18)\end{array}$ \\
\hline 3 & $\begin{array}{c}\text { M62 - Sepsis } \\
4 \%(n=12)\end{array}$ & $\begin{array}{c}\text { M58 - Medical Other } \\
5.6 \%(n=17)\end{array}$ \\
\hline 4 & $\begin{array}{c}\text { M15 - Acute coronary syndrome } \\
3.6 \%(n=11) \\
\text { M24 - Gastrointestinal other }(3.6 \% \\
n=11) \\
\text { T03A - Head wound } \\
3.6 \%(n=11)\end{array}$ & $\begin{array}{c}\text { M05 - Chest infection } \\
5 \%(n=15)\end{array}$ \\
\hline 5 & $\begin{array}{c}\text { D02 - Overdose (non opiate) } 3.3 \% \\
(n=10) \\
\text { M05 - Chest infection } \\
3.3 \%(n=10)\end{array}$ & $\begin{array}{c}\text { M57 - Syncope (faint) } \\
4 \%(n=12)\end{array}$ \\
\hline
\end{tabular}

